\title{
IMPACTS OF DEEP WATERWAY PROJECT ON LOCAL CIRCULATIONS AND SALINITY IN THE CHANGJIANG ESTUARY, CHINA
}

\author{
Jianzhong $\mathrm{Ge}^{1}$, Pingxing Ding ${ }^{1}$ and Changsheng Chen ${ }^{2}, 1$
}

\begin{abstract}
With an aim to improve and maintenance water depth along the navigational channel, the Deep Waterway Project has been conducted in the Changjiang Estuary. The structures of dikes and groins have greatly changed the local circulation with the combined effects of astronomical tide and strong freshwater discharge. A high-resolution fully three-dimension unstructured-grid model (FVCOM) has been applied to study the complicated hydrodynamics with the implementation of unstructured-grid dike-groin module. With the model validation with observation data, the simulation shows the dikes and groins has converted the rotational current into reciprocating flow along the navigational channel between the dikes, and produced the geometrically controlled eddies. The significant southward crossover current was produced along the dike during high tide when the water level is higher than the dike height. The strong saltwater intrusion is also revealed in the observation and model simulation.
\end{abstract}

Keywords: Deep Waterway Project; dikes; unstructured-grid modeling

\section{Introduction}

The abundant supply of discharge and sediment in the Changjiang Estuary produces significant turbidity maximum in the river mouth with the relatively shallow bathymetry (about $6 \mathrm{~m}$ deep) near the mouth, which limits the navigational potentials. As parts of the Deep Waterway Project (hereafter referred as DWP), shown in Fig.1, a group of dikes and groins was designed and built around the Changjiang Estuary, combined with dredging to deepen the navigational channel from $6.5 \mathrm{~m}$ in 1997 to $8.5 \mathrm{~m}$ in 2000 (Phase I), and $10.0 \mathrm{~m}$ in 2005(Phase II). Two dikes are constructed in the North Channel to reduce the sediment transport from the shallow Jiuduansha and Hengsha Shoals, and groynes are designed to strengthen the currents in the middle of channel, with an aim to maintenance the depth along the channel.

The construction has caused significant hydrodynamic change of the distributions of the local circulation and salinity around the Project and adjacent regions (Liu, 2008). The velocity amplitude along the main channel has been significantly increased, which favors the maintenance of the channel depth due to the decreasing of the sedimentation near the channel region (Hu and Ding, 2009). The dikes and groins has produces a totally different pattern of local circulation and its related salinity distribution. The dikes along both sides if shipping channel has greatly blocked the south-to-north current from Jiuduansha Shoals to Hengsha Shoals during the flood tide, and thus converted original rotational tide-controlled current system into the reciprocating flow. For this new circulation system, several measurement and model simulation has been conducted to study the hydrodynamics around this region ( $\mathrm{Hu}$, et al., 2008; $\mathrm{Wu}, 2007$ ), however, previous model simulation faced the limitation of low spatial grid resolution and the geometric fitting for the dikes and groins. This local river-coast engineering requires the higher spatial resolution to reveal the detailed hydrodynamic structures in the navigation channel and nearby shallow regions. And geometric fitting for the dikes and groins is a big issue for curvilinear orthogonal grid.

The other issue is how to consider the dikes and groins in the model calculation. These dikes are built about $30 \mathrm{~cm}$ above the mean sea level, which means these dikes could be submerged during the high tide and would be exposed during the low tide. Thus we can't treat them as solid walls due the existence of the water transport between the dikes. And the geometric width of dike and groins is about several meters, which is incomparable with the model grid size (about hundreds meters to thousand meters). The previous treatment is to consider these dikes as bathymetry slope and use the bedconforming method. This methodology artificially changes seabed bathymetry and fluid dynamics between the dikes.

In this paper, an unstructured-grid, high-resolution, Finite Volume Coastal Ocean Model (Chen, et al, 2006), implemented with the dike-groin module (Ge, et al, 2010), has been applied for the study of hydrodynamic variations of currents and salinity due to the construction. The rest of this paper is organized as follows. In section 2, the dike-groin module and model setup for the high-resolution

\footnotetext{
${ }^{1}$ State Key Laboratory of Estuarine and Coastal Research (SKLEC), East China Normal University, 3663 North Zhongshan Road, Shanghai, 200062, CHINA

2 School for Marine Science and Technology (SMAST), University of Massachusetts-Dartmouth, 706 South Rodney French Blvd, New Bedford, MA 02744, United States
} 
model will be briefly described. The section 3 discusses the model result and model-data analysis. Finally, the discussion and conclusion will be summarized in the section 4 .

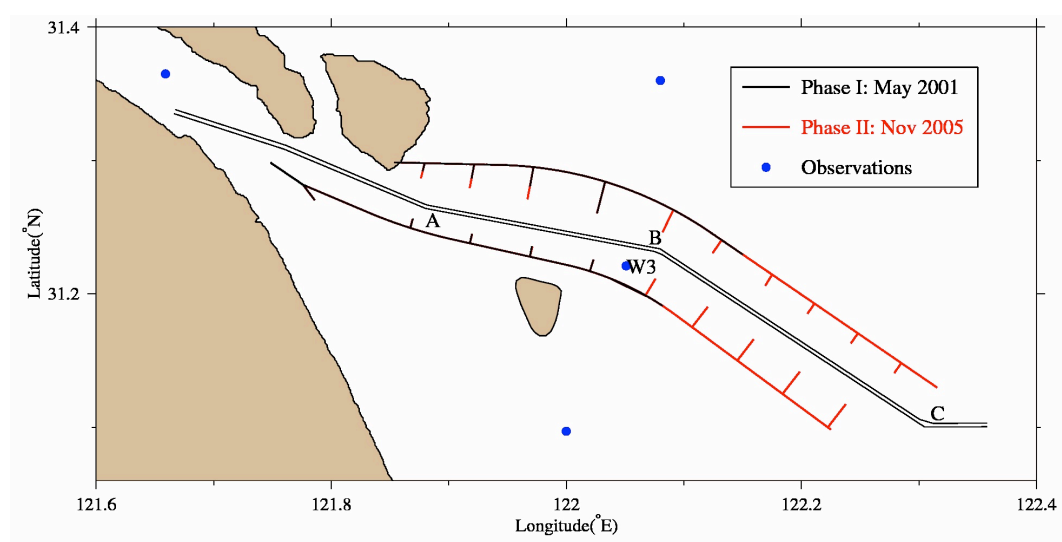

Figure 1. Schematic map of Deep Waterway Project in the Changjiang Estuary. Black lines indicate the dikes and groins that were built during Phase I project (finished in May 2001) and red lines show the dikes and groins during Phase II project (finished in Nov 2005). The blue points denote the observation stations with W3 near the shipping channel (every dry and wet season from 2003a to 2009a). A, B and C denote three control segments along the channel.

\section{Dike-groin module and model setups}

The consideration of dikes and groins is a critical issue for the coastal engineering practices in the numerical simulation. For the geometric complexity, the structure or curvilinear grid is more difficult to resolve coast-engineering structures' geometries. The unstructured-grid has the nature capability of providing the perfect geometric fitting for the irregular structures (Chen et al., 2006). The unstructuredgrid Finite-Volume Coastal Ocean Model (hereafter referred as FVCOM) has the ability to consider the irregular boundaries and also to provide the high-resolution modeling around the dike region. The dikes and groins are built about $30 \mathrm{~cm}$ above the mean sea level, which means that these constructions could be submerged during high tide and exposed during the low tide with the moderate average tide range about $2.66 \mathrm{~m}$ (with maximum record $4.62 \mathrm{~m}$ ) around this region (Chen et al., 1988). For the submergence and exposure of the dikes and groins, the thin-dam method has been applied in the coastal engineering modeling (Delft Manual, 2008). Based on the unstructured-grid FVCOM and thin-dam methodology, the unstructured-grid dike-groin module has been developed and implemented with an aim to consider the physical impact of the coastal constructions, and is capable of realistically resolving the narrow width of dikes and groins with free exchange in the upper column and used the original control volume to calculate the scalar variables such salinity, temperature and surface elevation (panel a of Fig.2) and solid blocking happens in the lower column, then original control volume is divided into two separate volumes to calculate scalar variables separately (panel b in Fig.2) (Ge, et al., 2010). This module has been applied to consider the series of dikes and groins in this paper.

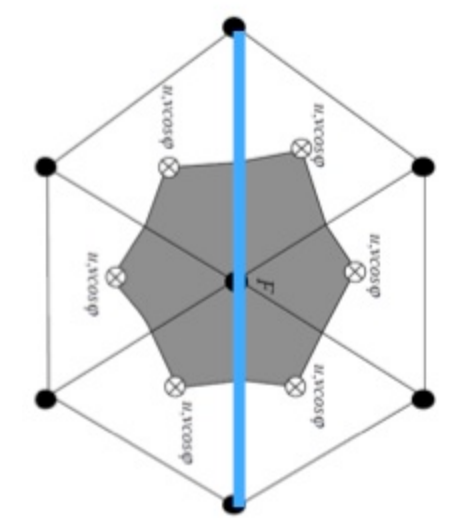

a) Upper column

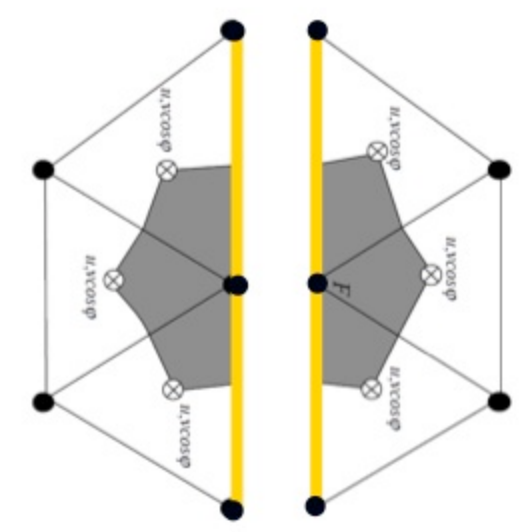

b) Lower column

Figure 2. Control volume treatment for scalar variable calculation for unstructured grid in FVCOM. 
The phase I of DWP was completed in May 2000 (black lines in Fig.1). Since then Phase II was carried out continuously and completed in August 2005 (red solid line in Fig.1). To reveal the local hydrodynamics around the DWP region, a high-resolution Changjiang River Estuary model has been set up. The unstructured grid covers the Changjiang River, the Hangzhou Bay and inner shelf of the East China Sea (Fig.3), and has the high resolution about $250 \mathrm{~m}$ around the local DWP region (right two panels in Fig.3) and 1-2km outer shelf, and 5-10km near the inner shelf and open boundary.

The high-resolution Changjiang River Estuary model has been configured as realistic simulation with the inclusion of the daily upstream freshwater discharge from the Changjiang River, realistic surface wind forcing and eight major astronomical tidal forcings along lateral boundaries. In this paper, the modeling procedures has been organized as follows, firstly, the model validation has been conducted with observation data including dry season (February 2006) and flood season (July 2007). Secondly, two numerical simulations, which are set at May 2000 (Phase I condition) and Aug 2005 (Phase II condition), are performed to study the local hydrodynamics.

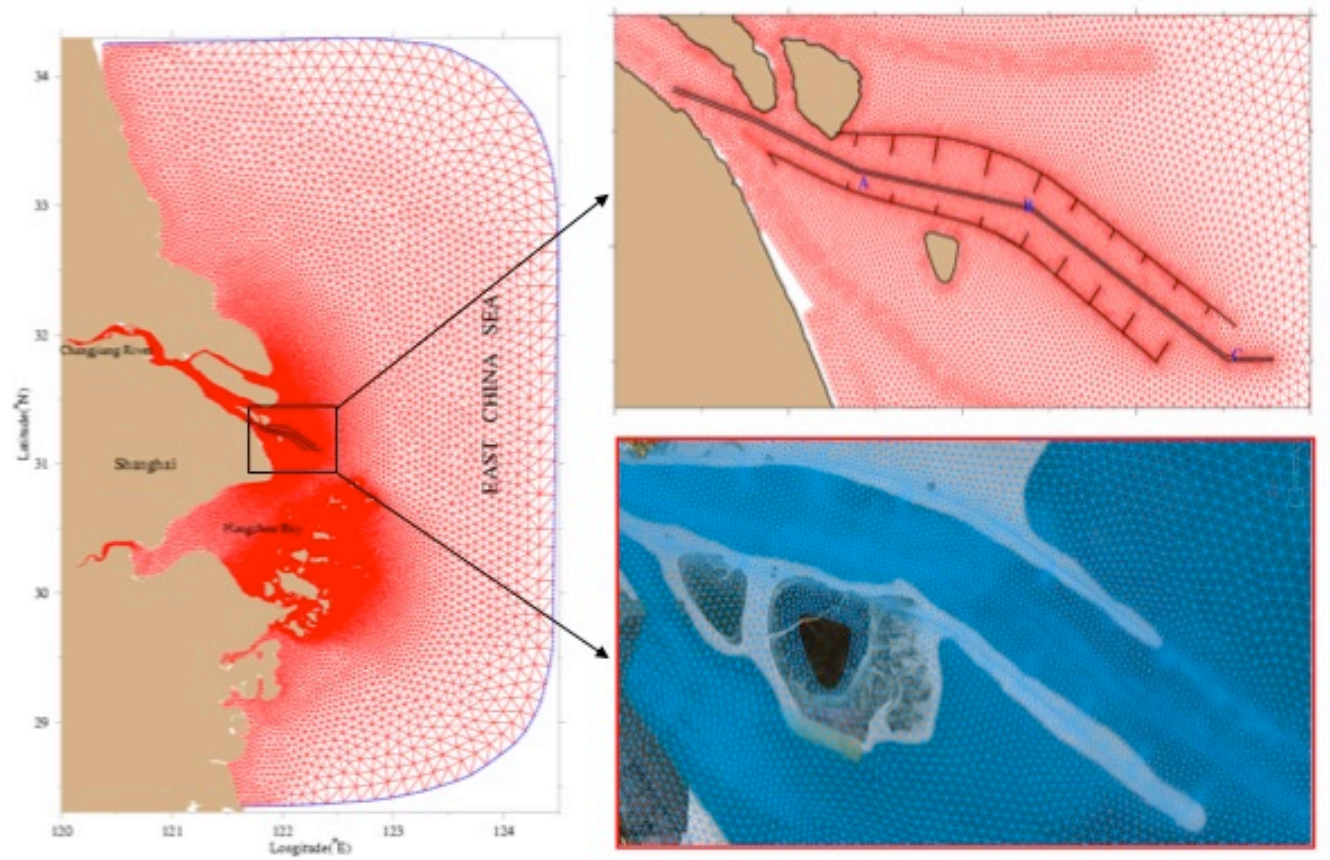

Figure 3. High-resolution unstructured grid for the Changjiang Estuary, adjacent coastal regions and inner shelf of East China Sea. Right two panels show the enlarged view for the Deep Waterway region.

As the bathymetry around the DWP region has been significantly changed due to the local construction, the sedimentation processes and channel dredging, the seasonal bathymetry data has been collected from 2000 to 2008(Pan, et al., 2010). Individual local bathymetry around the DWP region for specific time period was adapted for each simulation.

Validations and calibrations of the model simulation in the Changjiang Estuary and inner shelf of the East China Sea have been conducted in Ge, et al (2008). Additional model validation has been performed near the shipping channel. Blue points are the observation stations during February 2006 and July 2007, which is shown in Fig.1. The model-data velocity comparison for W3 station is shown in Fig.4 (Due to page limit, the model data comparisons for other stations are not included). The velocity comparison for surface, middle and bottom layer are shown in first, third and fifth row, respectively. The related current direction comparisons are included in second, fourth and sixth row. Left column shows the comparisons for dry season and right column shows the wet season's comparison. These model-data comparisons indicate that the high-resolution model has produced reasonable simulation for both wet and dry season. The current amplitude in the summer time is significantly bigger than that in the dry season due to the strong freshwater discharge impact in the wet season. And it also shows the constant current direction, about 120-degree eastern ward, during the ebb tide, which is caused by the boundary blocking effect of the two dikes. Before the construction of dikes and groins, the current system in this region shows the typical rotational characteristics that are 
dominated by the astronomical tide. It has been changed to the alternating flow with the blocking of the double dikes. The current transient period is relatively short.
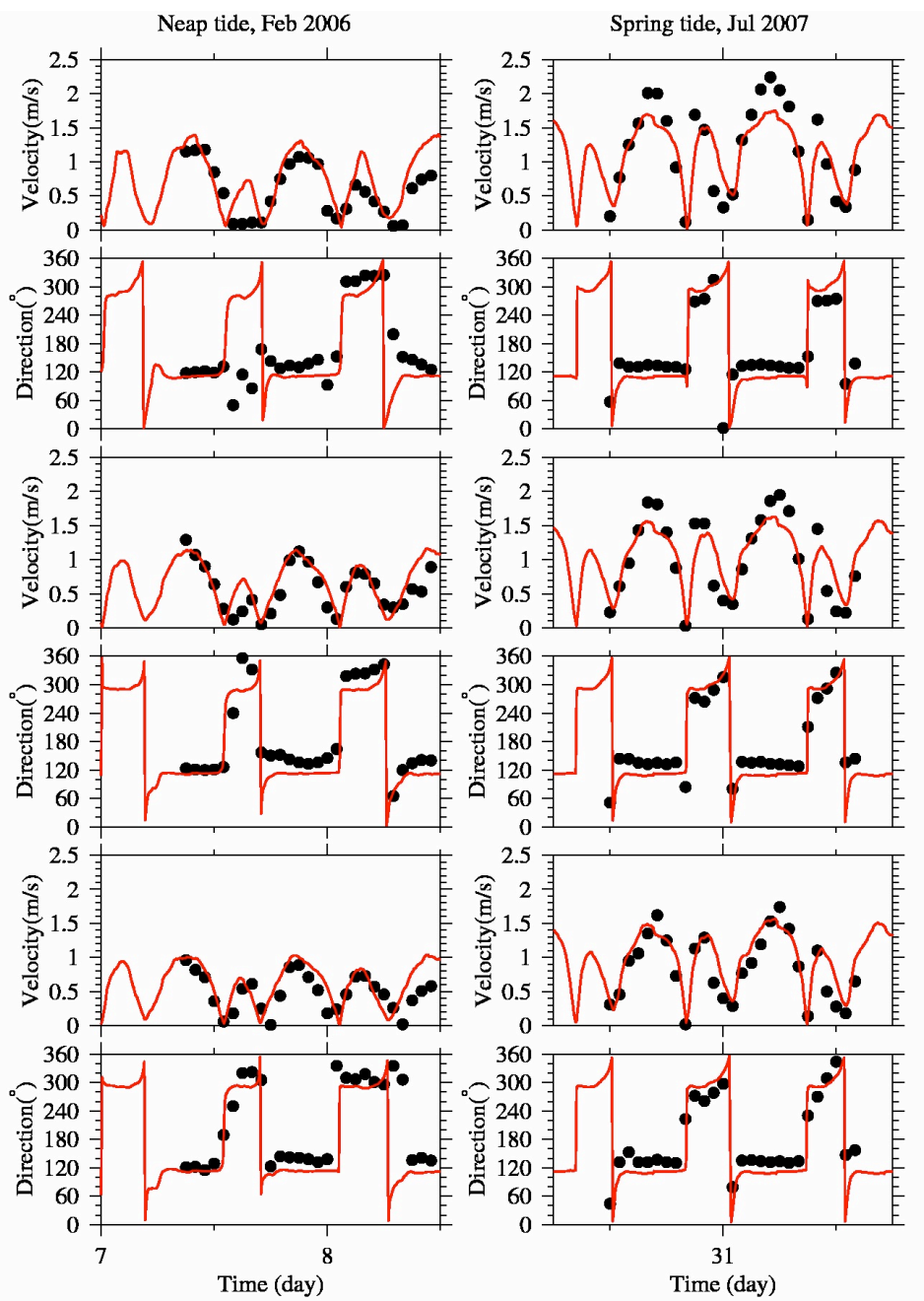

Figure 4. Model-data comparison for velocity and current direction at surface (upper two rows), middle (middle two rows) and bottom (lower two rows) layers. The black points indicate the observation data, and the red curves show the model result.

The corresponding salinity comparisons for two seasons are shown in Fig.5. The first, second and third row shows the salinity comparison for surface, middle and bottom layer, respectively. It shows the significant saltwater intrusion process during the flood tide on both wet and dry season. And this intrusion has the similar pattern in wet and dry seasons; however, the amplitude in the dry season is relatively bigger that that in wet season. In the dry season of 2006, the freshwater discharge rate is about $11000 \mathrm{~m}^{3} / \mathrm{s}$, which is significantly less than the summertime discharge rate about $43000 \mathrm{~m}^{3} / \mathrm{s}$. Under the smaller discharge rate in the dry season, the tide effect on the shipping channel in greatly increased thus produced stronger saltwater intrusion. During the wet season of bigger run-off, there still has the strong saltwater intrusion during flood tide (shadow region in the right panel of Fig.5). 

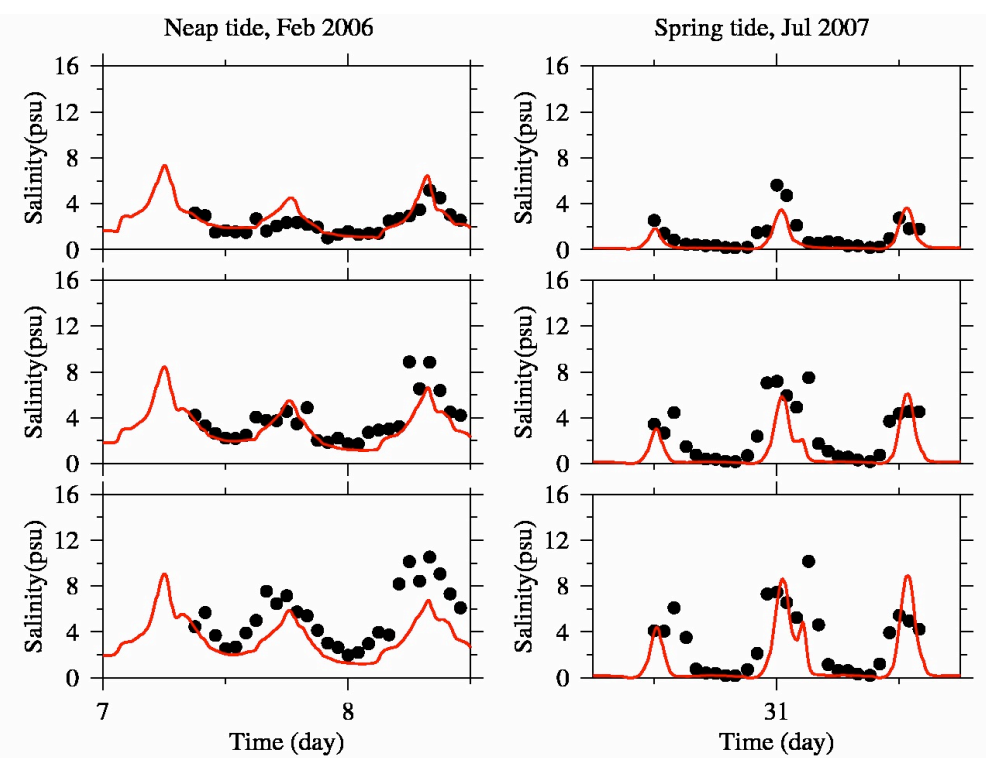

Figure 5. Model-data comparison for salinity at surface (upper panel), middle (middle panel) and bottom (lower panel) layers. The black points indicate the observation data, and the red curves show the model result.

Based on the regional and local model validations for current and salinity, two numerical experiments are set up, with aiming to examine the dynamic characteristics at two engineering phases of DWP, which are at May 2001 (Phase I project finished) and August 2005 (Phase II project finished). These two experiments adapt the same external forcings, such as surface wind forcing, astronomical tidal forcing and upstream freshwater impact at the Changjiang River. These external forcings all used the data at July 2005 when the Changjiang River had its typical summertime discharge rate about $40000 \mathrm{~m}^{3} / \mathrm{s}$. The differences between two experiments are the local bathymetry and the configurations of dikes and groins. In Phase I case, the bathymetry in May 2001 was used. The dikes and groins, which were finished in Phase I (black lines in Fig.1), were considered in the experiment. For Phase II case, the simulation used the bathymetry in June 2005 and the all dikes and groins.

\section{Comparisons and analysis}

The constructions of dikes and groins have caused significant impact on the local hydrodynamics, especially the circulation patterns. Before the DWP, this region has the typical rotational current system, which are mainly controlled by the moderate tide forcing. After the buildings of these coastal engineering, the flow system has been totally changed into alternating current system. Because of the blocking effect of dikes, the northwestward flood tide and southeastward ebb tide are greatly decreased around the channel region. The typical surface current distributions at flood maximum are shown in Fig.6. In Phase I, the outer is still controlled by the rotational tide (left panel of Fig.6); the velocity amplitude is spatially smooth. The situation has been shifted in the Phase II; the current amplitude along the shipping channel is significantly bigger than that of other region due to the constraint effect of dikes and groins. However, the current direction is not exactly along the shipping channel, which has a shift toward the north dike (eclipse in Fig.6). The phenomenon is identical with the morphological evolution in this area, where has been greatly eroded and created relatively deeper region than channel (Pan, et al., 2010).

During the high tide, the dikes, which are about $30 \mathrm{~cm}$ above the mean sea level, cannot block the flood current totally. Thus the significant crossover currents are produced along the dikes. 


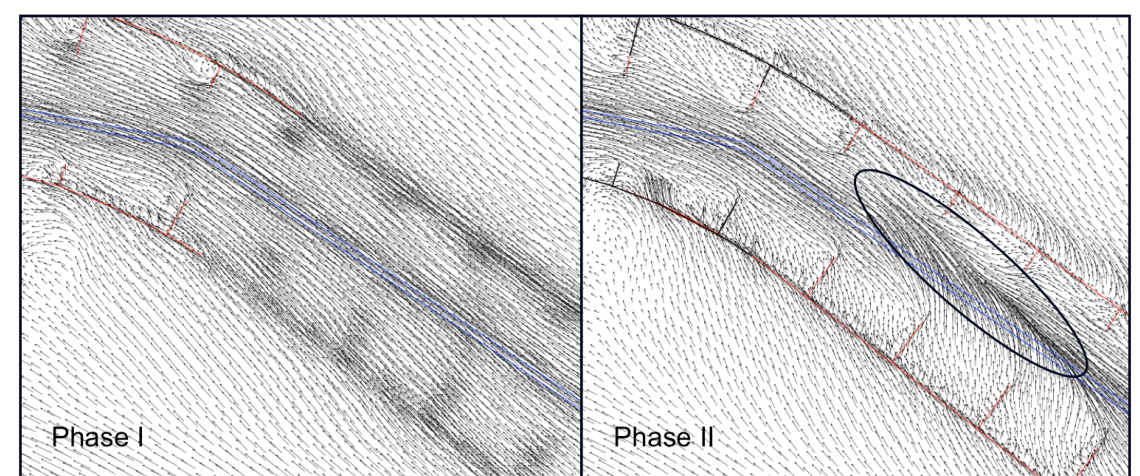

Figure 6. Surface current distribution at flood maximum after Phase I (left) and Phase II (right).

The surface distributions for the typical ebb maximum are shown in Fig.7. It has similar pattern as that of flood maximum. However, the north dike could now block ebb tide current from the Hengsha Shoal totally because the tide water level is less than the dike height during the low tide. It has caused some small-size eddies around the groins. The size of eddies is mainly controlled by current amplitude and the length of nearby groin. During the ebb tide, the current flow mainly along the channel, and has no significant lateral shifting. Therefore, the current amplitude along the channel is significantly increased in the lower region of DWP. This current pattern favors the erosion process to maintenance the shipping depth along the channel (Pan, et al., 2010).

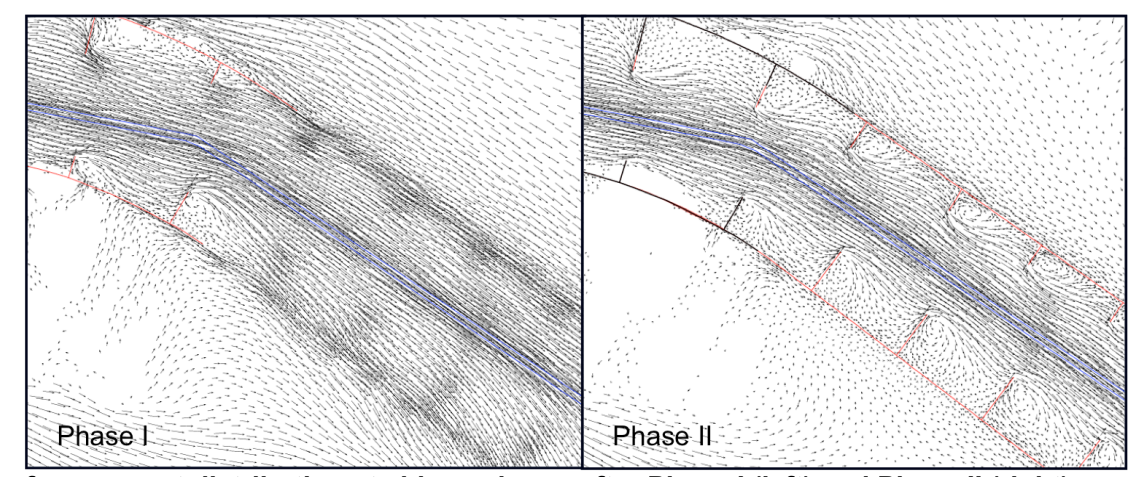

Figure 7. Surface current distribution at ebb maximum after Phase I (left) and Phase II (right).

Since the along-channel velocity has critical influence on the channel maintenance and dredging procedure, and the channel sedimentation is very sensitive to the velocity amplitude increasing or decreasing (J. Liu, 2008). And the along-channel velocity has noticeable difference between Phase I and Phase II conditions.

The distributions of along-channel velocity profiles at Phase I and Phase II during the ebb tide maximum are shown in Fig.8. Both distributions show relatively bigger velocity amplitude in the downstream region from segment B to segment C. It reaches about $2.4 \mathrm{~m} / \mathrm{s}$ in the surface in Phase I condition. After the additional dikes and groins were built during the Phase II project, the velocity amplitude has been increased due to the flow constraint effect. The amplitude has reached $3 \mathrm{~m} / \mathrm{s}$ in the lower region. In the region between segment $\mathrm{B}$ and $\mathrm{C}$, the amplitude of along-channel velocity in Phase II condition has about $40 \sim 60 \mathrm{~cm} / \mathrm{s}$ increasing compared with Phase I condition. However, the situation reverses in the middle region from segment $\mathrm{A}$ to segment $\mathrm{B}$. The along-channel velocity has about $20 \mathrm{~cm} / \mathrm{s}$ decreasing in Phase II condition.

The significant difference of along-channel velocity during the flood maximum happens on the upper region from the western starting point to segment B. It has been decreased with the amplitude about $20 \mathrm{~cm} / \mathrm{s}$ in Phase II condition in the upper region. In the lower region, the position of velocity maximum has an upstream-ward shifting about $10 \mathrm{~km}$ distance and the velocity amplitude doesn't have noticeable change. It is consistent with horizontal structure in Fig.6, in which flood current has the northward shifting. 


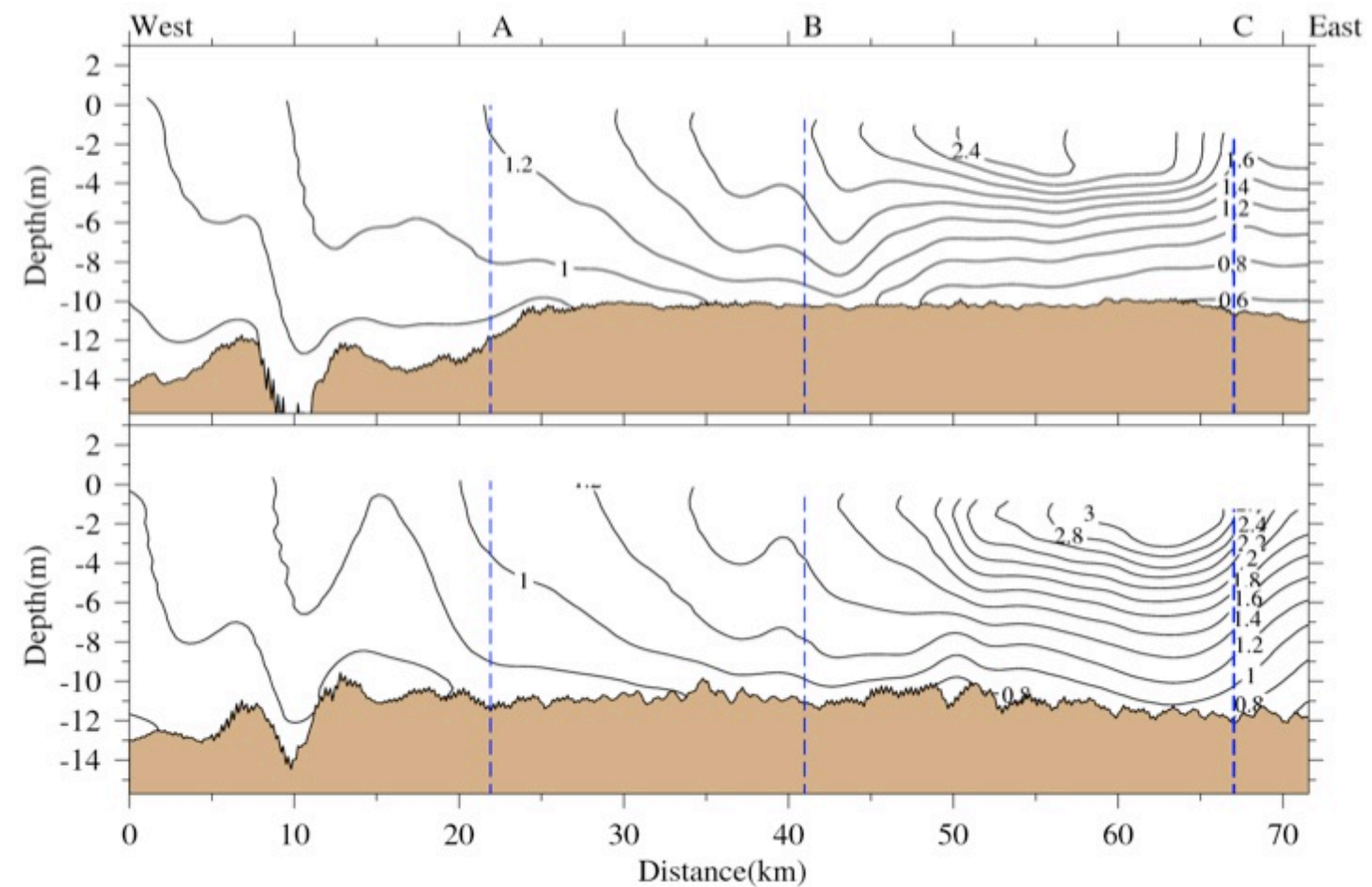

Figure 8. Along-channel velocity profile during ebb maximum at Phase I (upper panel) and Phase II (lower panel).

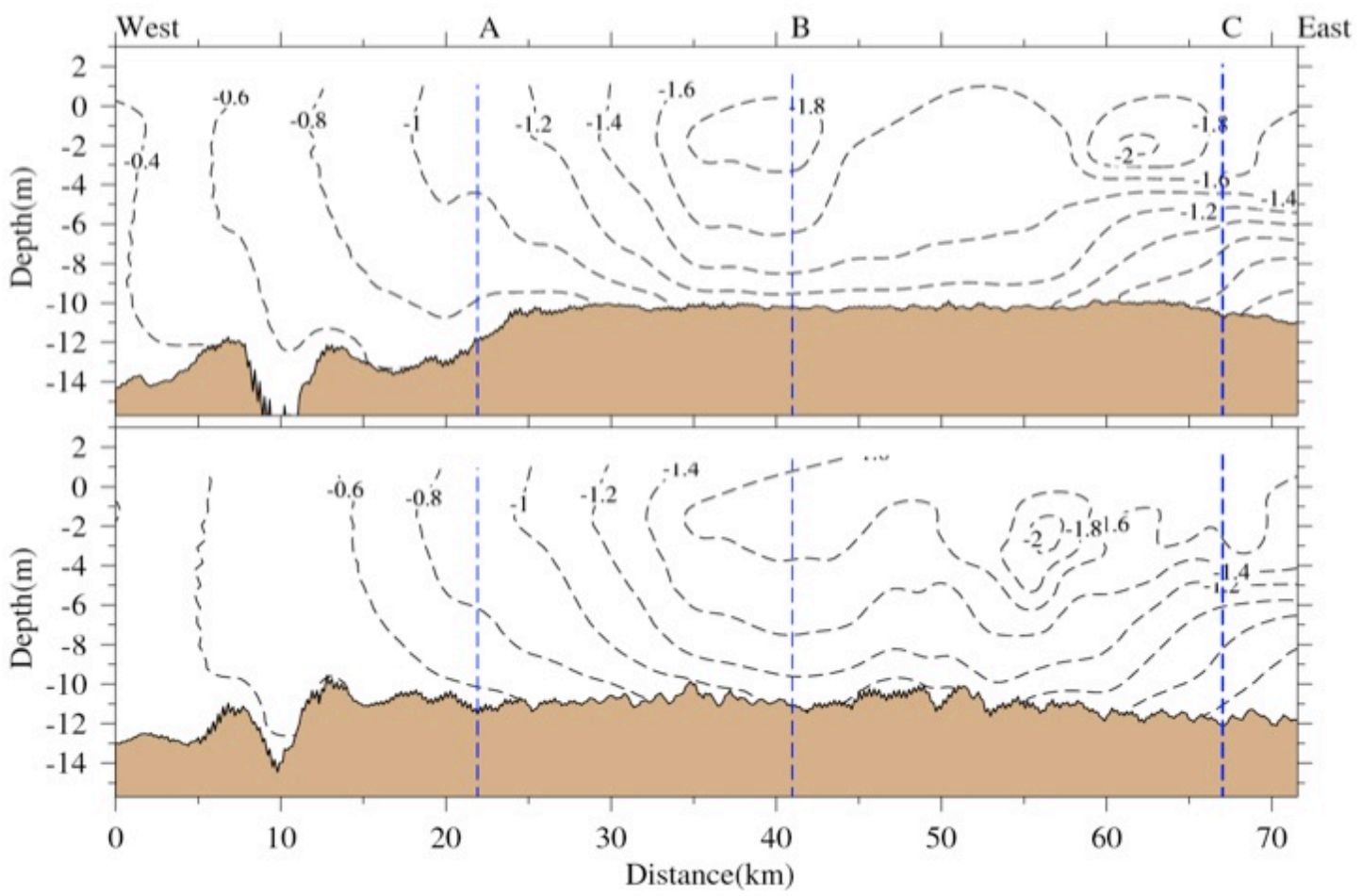

Figure 9. Along-channel velocity profile during flood maximum at Phase I (upper panel) and Phase II (lower panel).

DWP region is the frontline between freshwater discharge from upstream river and the saltwater from the open ocean. The mixing process mainly happens in this area. Therefore, the constructions have quite significant impact on the salinity distribution during the two phases of DWP. Fig.10 shows the salinity distributions during flood tide maximum at Phase I case (left column) and Phase II case 
(right column). These two situations at Phase I and II both show the strong saltwater intrusion from the bottom layer. These intrusions can reach the middle area during the flood tide. And the surface and bottom salinity distributions indicate that the vertical stratification has been increased in the eastern part of shipping channel. Some low-salinity water has been blocked in the groin region in the eastern part after the Phase II has finished. Due to the northward off-channel shifting of flood tide current at Phase II condition, the salinity distribution shows strong northward advection effect and there was no low-salinity water left in the groin region. At Phase II situation, the low-salinity water mainly dominates the surface layer, and the saltwater from the open ocean controlled the bottom layer. A strong two-layer system has been revealed in the eastern part of DWP where has new dikes and groins during Phase II project.

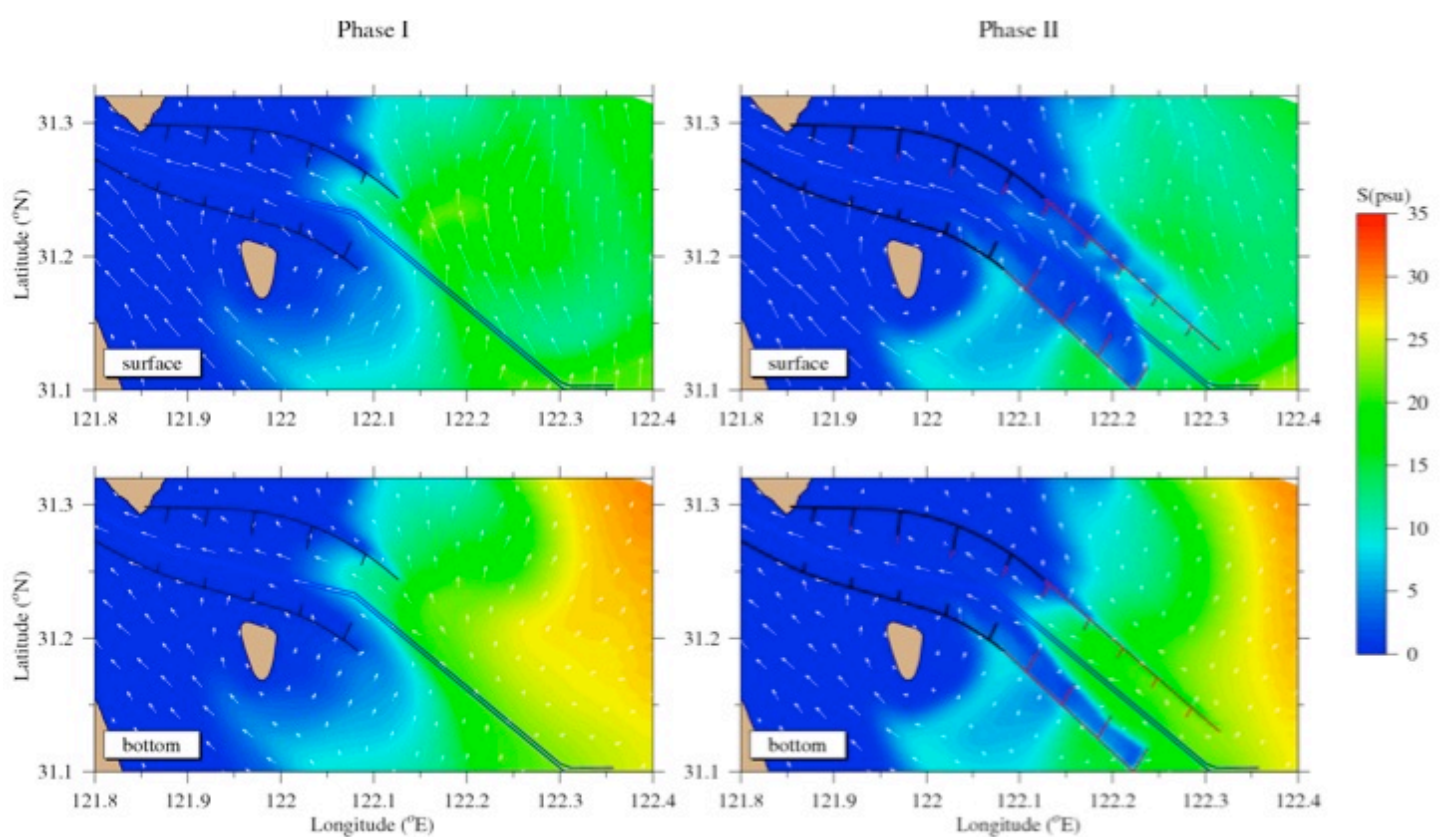

Figure 10. Comparisons for salinity distributions at flood maximum after Phase I (left column) and Phase II (right column).

\section{Conclusion}

An unstructured-grid, high-resolution, dike-groin module implemented FVCOM model for the Changjiang Estuary and adjacent coastal region has been applied to study the impacts of Deep Waterway Project on the local hydrodynamics, with a focus on the local circulations. With the modeldata comparisons for current and salinity, this FVCOM-CJ has provided reasonable simulation around this region, and revealed the local circulation patterns. These hydrodynamic impacts are examined with two idealized numerical experiments at Phase I and Phase II situations.

The constructions of dikes and groins around the Deep Waterway Project have resulted in the significant changes on the local circulations, including the small-size eddies generated in the groin region, cross-over current along the dikes during the high tide when the water level is higher than the dike elevation, and converting the original rotational current system into alternating flow along the shipping channel. From Phase I to Phase II, the along-channel current has some changes on the velocity amplitude and current direction. Significant velocity increasing due to the constraint effect of dikes is revealed in the eastern part of DWP. Small amplitude changes at the upstream western part have been found, with decreasing amplitude about $20 \mathrm{~cm} / \mathrm{s}$ during the flood tide. Strong bottom saltwater intrusion is also revealed in the model-data comparison and the idealized experiments. The significant stratification indicates a two-layer system in eastern part of DWP, with the low-salinity water dominated the upper column and salty ocean water controlled the lower column.

The shipping channel has a width just about $300-400 \mathrm{~m}$, which requires further high-resolution modeling to reveal much more detailed circulation structures in the channel region and groin region. This paper is the preliminary study with the $250 \mathrm{~m}$-resolution. The further studies with much higher resolution (100m and $50 \mathrm{~m}$ resolution), additional constructions of DWP and more observation data are being conducted. It should be noted that the comparison and analysis are only focused on the idealized 
experiments; the results in this paper should be interpreted carefully when considering the realistic situations with different freshwater discharge, wind forcing, local bathymetry and most importantly, different engineering configurations in DWP region.

\section{ACKNOWLEDGMENTS}

Jianzhong Ge and Pingxing Ding are supported by the Global Change Scientific Research Program of China (No. 2010CB951200), PhD Program Scholarship Fund (2009010) of East China Normal University, and State Scholarship Fund from China Scholarship Council. C. Chen serves as Zi Jiang Scholar at the State Key Laboratory for Estuarine and Coastal Research, East China Normal University (ECNU) and supported by the Open Research Fund of SKLEC. The dike-groyne module was developed with staff technical support through the US NOAA-funded Northeastern Regional Association of Coastal Ocean Observing Systems (NERACOOS).

\section{REFERENCES}

Chen, J., H. Shen and C. Yun, (1988). Morphological processes and evolutions in the Changjiang Estuary. Shanghai Science and Technology Press, pp1-3 (in Chinese)

Chen, C., G. Cowles and R. C. Beardsley, (2006a). An unstructured grid, finite-volume coastal ocean model: FVCOM User Manual. Second Edition. SMAST/UMASSD Technical Report-06-0602, pp 45.

Chen, C., R. C. Beardsley and G. Cowles, (2006b). An unstructured grid, finite-volume coastal ocean model (FVCOM) system. Special Issue entitled "Advance in Computational Oceanography", Oceanography, vol. 19, No. 1, 78-89.

Delft3d-Flow User Manual, (2008) Simulation of multi-dimensional hydrodynamic flows and transport phenomena, including sediments, Deltares, Rotterdamseweg 185, p.o. box 177, $2600 \mathrm{MH}$ Delft, The Netherlands

Ge, J., Ding. P., Chen. C. and Xue. P., (2008), Low-salinity plume in the Changjiang and adjacent coastal regions: a model-data comparison, Proceedings of the 31st International Conference of Coastal Enginnering 2008, Hamburg, Germany, pp4471-4481

Ge, J., C. Chen, J. Qi, P. Ding, and R. C. Beardsley, (2010), Development of A Dike-Groyne Module in A Three-Dimensional Terrain-Following Coordinate Coastal Ocean Model (FVCOM): A Tool for River-Coast Ocean Engineering Applications, submitted to Journal of Waterway, Port, Coastal, and Ocean Engineering

HU, F., H. Hu and G. Gu, (2002). Studies of fronts in the Changjiang Estuary, East China Normal University Press, pp35, (in Chinese)

Hu, K. and Ding, P., (2009). The effect of deep waterway constructions on hydrodynamics and salinities in Yangtze estuary, China. Journal of Coastal Research. SI 56 (Proceedings of the $10^{\text {th }}$ International Coastal Symposium),961-965. Lisbon, Portugal, ISSN 0749-0258

Liu, J., (2008). Study on morphological evolution and siltation in deep waterway due to channel reconstruction in the North Passage, Yangtze Estuary. Doctoral degree thesis of the East China Normal University, pp38-55. (in Chinese)

Pan, L, P. Ding and J. Ge. (2010). Analysis of the influence of Deep Waterway Project on the morphological change in the North Passage of Changjiang Estuary. China. Journal of Sedment Research. (in press)

Wu, H., (2006). Saltwater Intrusion in the Changjiang Estuary----Impacts of Saltwater Spilling Over, Deep Waterway Project and Winter Monsoon. Doctoral degree thesis of the East China Normal University, pp 106-125. (in Chinese) 